American J. of Engineering and Applied Sciences 2 (2): 393-398, 2009

ISSN 1941-7020

(C) 2009 Science Publications

\title{
A Fast Series Active Filter using Sliding Mode Control to Correct and Regulate Unbalance Voltage in Three-Phase System
}

\author{
Theerayuth Chatchanayuenyong \\ Faculty of Engineering, Mahasarakham University, \\ T. Khamriang, A. Kantarawichai, Mahasarakham, 44150, Thailand
}

\begin{abstract}
Problem statement: A Sliding Mode Controller (SMC) with fast reference voltage generation to correct and regulate unbalance voltage in three-phase system was proposed. Approach: The compensation algorithm was not based on three-symmetrical component decomposition so the controller can yield a fast response that was essential in such a critical real time control work. The reference voltages were fed to the SMC, which was a robust closed loop controller. Results: The proposed algorithm and control scheme of series active filter could correct and regulate unbalance voltage in three-phase system under arbitrary fault conditions of the utility supply. Conclusion: A design example and its simulation results proved the concept and validated the proposed algorithm.
\end{abstract}

Key words: Sliding mode control, series active filter, power quality improvement, voltage unbalance, voltage sags, voltage swells

\section{INTRODUCTION}

Power quality in ac three-phase system could be analyzed by IEEE std. 1159-1995, for example; voltage unbalance, voltage sags, voltage swells, partial or total loss of one or more phases. Voltage unbalance can occur due to an incomplete transposition of transmission lines, unbalanced loads, open delta transformer connection, disconnected three-phase capacitor bank and the proliferation of nonlinear and large single-phase loads ${ }^{[1]}$. Voltage unbalance worsens the operation of $\mathrm{AC}$ electric machines. The negative sequence component in voltage unbalance causes large transient current that leads to reduction of the net torque, increase in losses and temperature rise ${ }^{[2]}$. These poor power qualities can degrade or damage the electrical equipment connected to the system.

The method to improve the power qualities can be done by using a three-phase series active filter, which can correct the unbalance voltage and regulate to the desired level.

At present, a number of algorithms and principles are proposed in the literature ${ }^{[3-7]}$. By the way, most of them are open loop control by using the decomposition of the three symmetrical components.

This study proposed a compensation algorithm using a Series Active Filter (SAF) associated with the sliding mode controller to correct and regulate the unbalance voltage in three-phase system. The principle of proposed voltage correction is not based on threesymmetrical component decomposition so the controller can yield a fast response that is essential in such a critical real time control work. Three SMCs are employed to shape the actual load voltage according to the reference voltage. SMC is a robust closed loop controller, which basically performs better than the conventional open-loop feed forward technique. The SAF employed for the compensation is composed of a three-phase PWM voltage source inverter injecting compensation voltages through three separate 1- $\phi$ transformers. The output of the inverter is connected to a second order filter to eliminate high frequency caused by the switching action of the inverter. The secondary winding of each transformer is connected in series with each phase of the power supply as shown in Fig. 1.

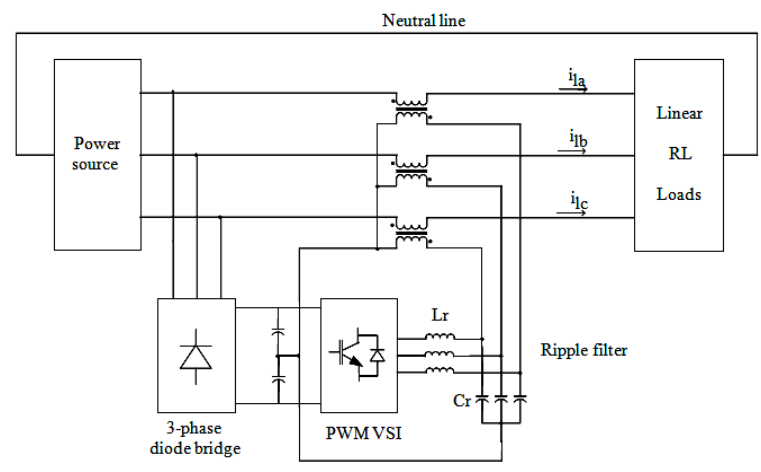

Fig. 1: Diagram of proposed series active filter (SAF) 


\section{MATERIALS AND METHODS}

Principle of voltage correction:

Reference voltage generation: The phasor diagram of a balanced voltage of utility three-phase line is shown in Fig. 2. The vectors formed by $\mathrm{v}_{\mathrm{ab}}, \mathrm{v}_{\mathrm{bc}}$ and $\mathrm{v}_{\mathrm{ca}}$ represent the line-to-line voltages while $\mathrm{v}_{\mathrm{a}}, \mathrm{v}_{\mathrm{b}}$ and $\mathrm{v}_{\mathrm{c}}$ represent the phase voltages.

Under fault condition, the voltage in each phase of Fig. 2 is unbalance. The instantaneous voltage of phase A with amplitude $\mathrm{V}_{\mathrm{a}}$ and phase angle $\phi$ can be written as shown in Eq. 1:

$\mathrm{V}_{\mathrm{a}}(\mathrm{t})=\mathrm{V}_{\mathrm{a}} \sin (\omega \mathrm{t}+\phi)$

This voltage can be derived by Eq. 2:

$\mathrm{v}_{\mathrm{a}}(\mathrm{t})=\mathrm{v}_{\mathrm{ab}}(\mathrm{t})-\mathrm{v}_{\mathrm{ca}}(\mathrm{t})$

where, $\mathrm{v}_{\mathrm{ab}}$ and $\mathrm{v}_{\mathrm{ca}}$ represent the instantaneous line-toline voltages shown in Fig. 2.

The amplitude, $\mathrm{V}_{\mathrm{a}}$, can be calculated from data in a short time window using two samples of the signal $\mathrm{v}_{\mathrm{a}}(\mathrm{t})$ as shown in Eq. $3^{[6]}$ :

$\mathrm{V}_{\mathrm{a}}=\frac{\left[\mathrm{v}_{\mathrm{a}(\mathrm{k}+1)}^{2}+\mathrm{v}_{\mathrm{a}(\mathrm{k})}^{2}-2 \mathrm{v}_{\mathrm{a}(\mathrm{k}+1)} \mathrm{v}_{\mathrm{a}(\mathrm{k})} \cos \left(\omega \mathrm{T}_{\mathrm{s}}\right)\right]^{0.5}}{\sin \left(\omega \mathrm{T}_{\mathrm{s}}\right)}$

Where:

$\mathrm{v}_{\mathrm{a}(\mathrm{k}+1)}$ and $\mathrm{v}_{\mathrm{a}(\mathrm{k})}=$ The phase-A voltage at instant $\mathrm{t}_{(\mathrm{k}+1)}$ and $\mathrm{t}_{(\mathrm{k})}$ Respectively

$\mathrm{T}_{\mathrm{s}} \quad=$ Sampling period equal to $\mathrm{t}_{(\mathrm{k}+1)^{-}} \mathrm{t}_{(\mathrm{k})}$

The reference voltages for the SMCs are calculated as given in Eq. 4 and 5:

$\mathrm{V}_{\text {ref }}(\mathrm{t})=\frac{\mathrm{V}_{\text {rated }}}{\mathrm{V}_{\mathrm{a}}} \times \mathrm{v}_{\mathrm{a}}(\mathrm{t})$

$\left[\begin{array}{c}\mathrm{v}_{\text {refa }} \\ \mathrm{v}_{\text {refb }} \\ \mathrm{v}_{\text {refc }}\end{array}\right]=\frac{1}{\sqrt{3}}\left[\begin{array}{ccc}1 & 1 & 1 \\ 1 & \alpha^{2} & \alpha \\ 1 & \alpha & \alpha^{2}\end{array}\right]\left[\begin{array}{c}0 \\ \mathrm{v}_{\text {ref }} \\ 0\end{array}\right]$

Where:

$\mathrm{V}_{\text {rated }} \quad=$ Rated amplitude of load voltage

$\alpha=e^{j 2 \pi / 3}=$ Phase-shift operator

Sliding Mode Controller (SMC): The reference voltage generated from Eq. 4 and 5 are fed to the SMC as shown in Fig. 3.

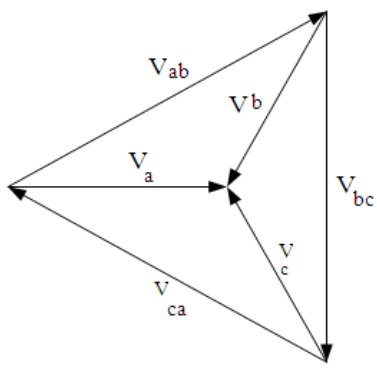

Fig. 2: Phasor diagram of a balanced voltage of utility three-phase line

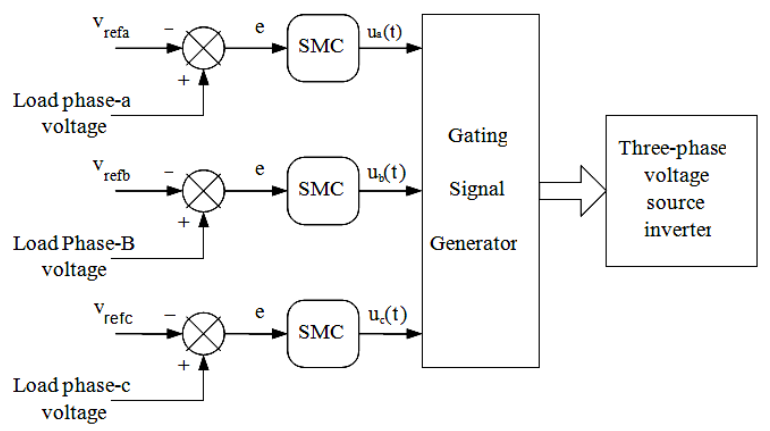

Fig. 3: Sliding mode controller block diagram

The variable structure control law of SMC is given by:

$u(t)=-\rho \operatorname{sgn}(s(t))$

or

$u(t)=\left\{\begin{array}{r}-\rho \text { if } s(x, t)>0 \\ \rho \text { if } s(x, t)<0\end{array}\right.$

Where:

$\rho \quad=$ Sliding gain

$\operatorname{sgn}(\cdot)=$ The signum or the sign function

The switching function $s(t)$ is defined by:

$\mathrm{s}(\mathrm{x}, \mathrm{t})=\mathrm{e}$

where, $\mathrm{e}$ is tracking error $=$ load phase voltage $-\mathrm{v}_{\text {ref }}$

PWM gating signal generation: The gating signals of the inverter are generated by comparing the control command, $u(t)$ in Eq. 7 with a triangular waveform whose frequency is kept constant at $6 \mathrm{kHz}$ as shown in Fig. 4. 


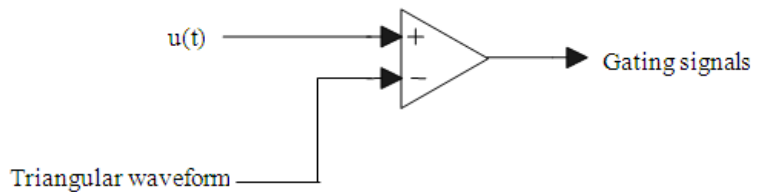

$(6 \mathrm{kHz})$

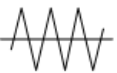

Fig. 4: Gating signal generation diagram
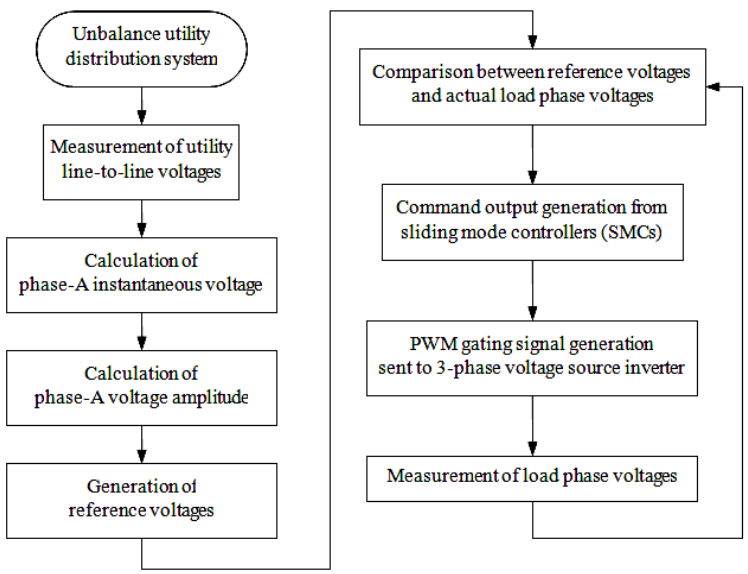

Fig. 5: Voltage Correction and regulation flowchart

Table 1: Design example

Utility supply frequency

Rated load phase voltage

Load power factor

Series transformer turn ratio

DC link voltage

Invert switching frequency

Filter inductance

Filter capacitance

Power circuit implementation: As shown in Fig. 1, the power circuit of the series active filter consists of a three-phase PWM voltage source inverter, three separate 1- $\phi$ transformers and a second order passive filter. The circuit design for the implementation can be found in ${ }^{[7]}$, hence it is not included here.

Voltage correction and regulation flowchart: The procedure to correct and regulate the unbalance voltage is shown in a flowchart (Fig. 5).

Design example: In order to prove and validate the concept of the proposed algorithm, a design example is done in accordance as the procedure illustrate above. The design parameters are shown in Table 1.

\section{RESULTS AND DISCUSSION}

The proposed algorithm has been verified by simulation. The results are given into 5 categories in accordance as the arbitrary imposed supply conditions, as shown in Fig. 6-10. In each case, the compensator begins to operate at $40 \mathrm{~m} \mathrm{sec}$.

In order to quantify the degree of unbalance in the voltages, an unbalance factor must be defined. The unbalance factor, UF is the ratio between the sum of zero sequence and negative sequence voltages $v_{0}+v_{2}$ and the positive sequence voltage $\mathrm{v}_{1}$ :

$\mathrm{UF}=\frac{\mathrm{v}_{0}+\mathrm{v}_{2}}{\mathrm{v}_{1}}$
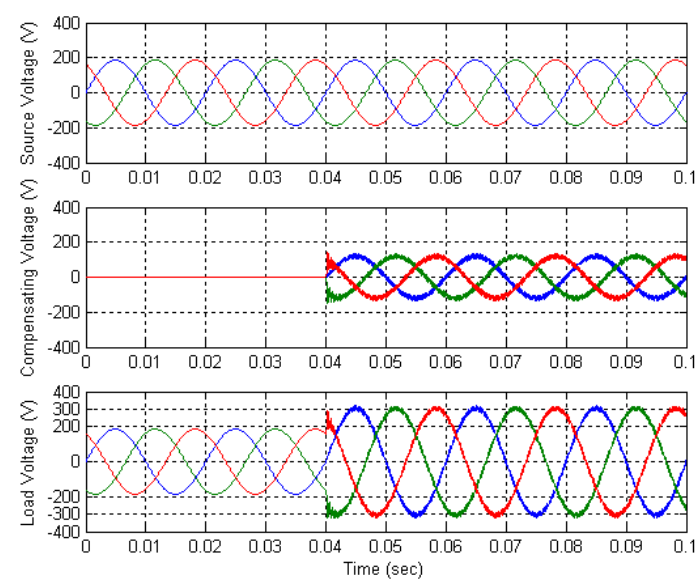

(a)
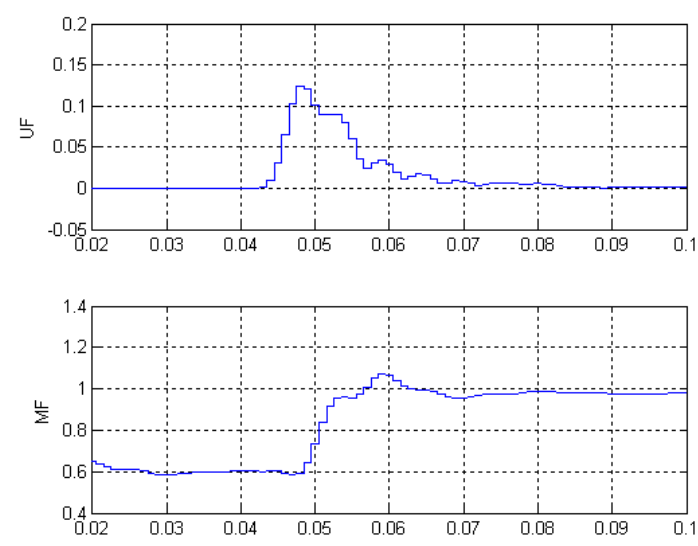

(b)

Fig. 6: (a): Load phase voltage, compensating voltage and source phase voltage in case of balance voltage sags with $|\mathrm{MF}|=0.60 ;$ (b): The corresponding UF and MF of load phase voltage 
Am. J. Engg. \& Applied Sci., 2 (2): 393-398, 2009

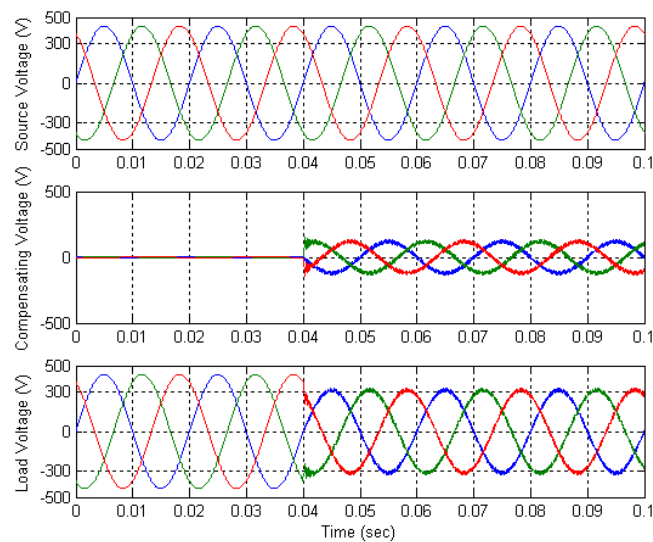

(a)
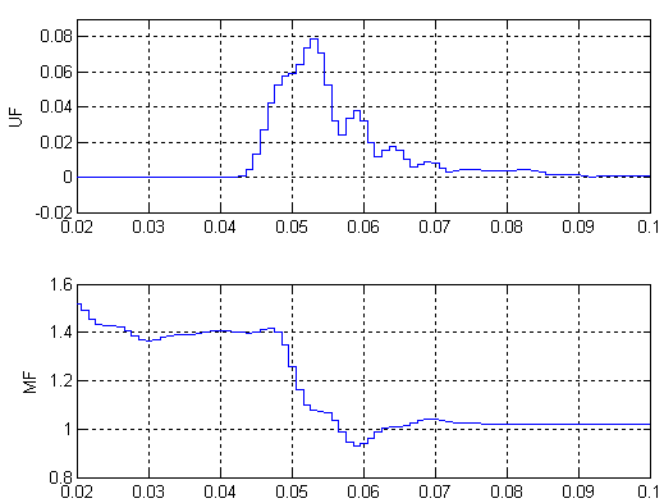

(b)

Fig.7: (a): Load phase voltage, compensating voltage and source phase voltage in case of balance voltage swells with $|\mathrm{MF}|=1.40$ : (b): The corresponding UF and MF of load phase voltage

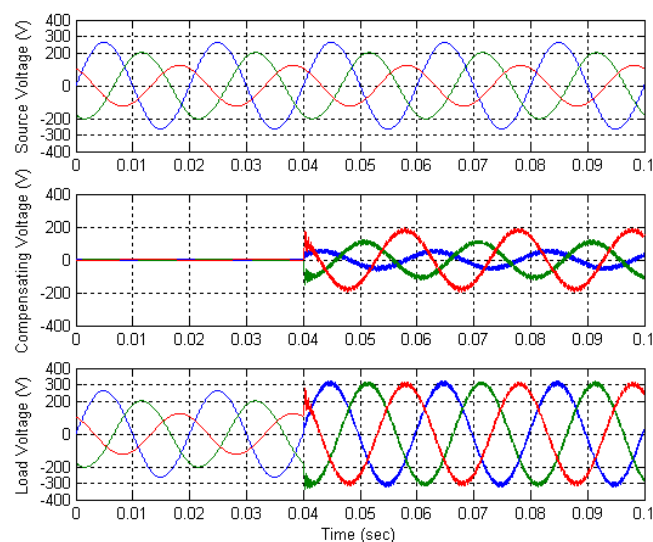

(a)
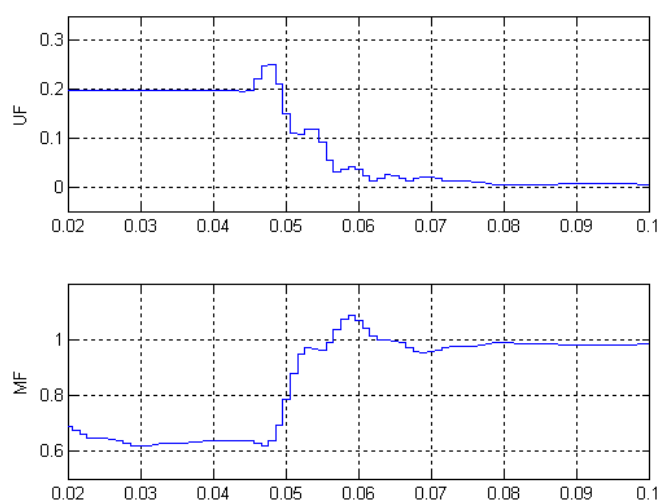

(b)

Fig. 8: (a): Load phase voltage, compensating voltage and source phase voltage in case of unbalance voltage sags with $|\mathrm{UF}|=0.20$ and $|\mathrm{MF}|=0.63$ (b): The corresponding UF and MF of load phase voltage

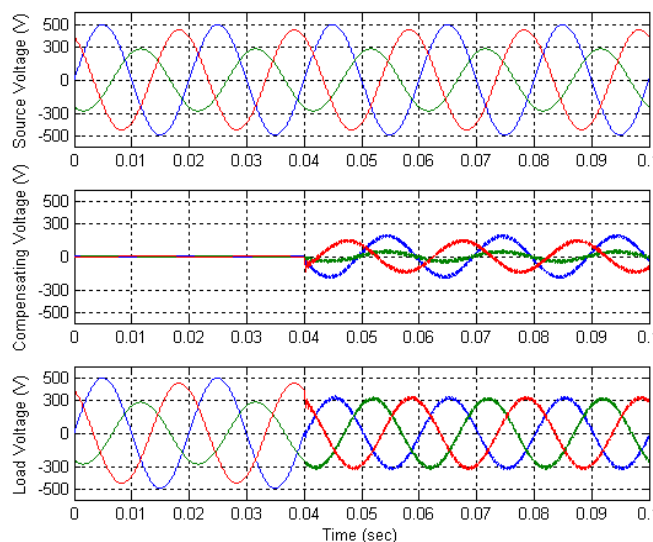

(a)
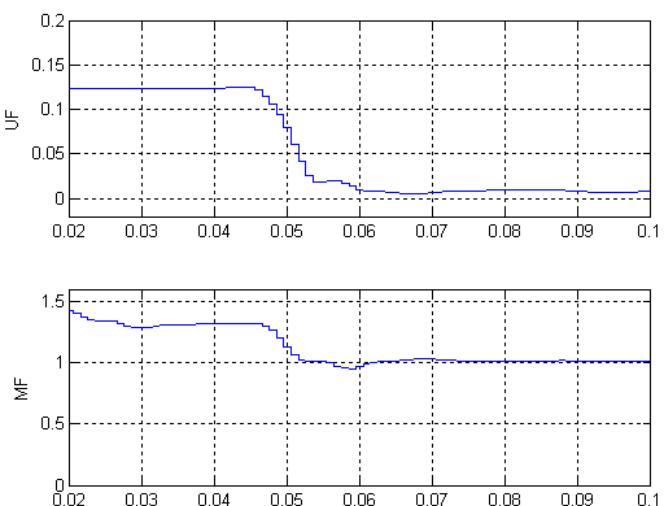

(b)

Fig. 9: (a): Load phase voltage, compensating voltage and source phase voltage in case of unbalance voltage swells with $|\mathrm{UF}|=0.12$ and $|\mathrm{MF}|=1.31$; (b): The corresponding UF and MF of load phase voltage 


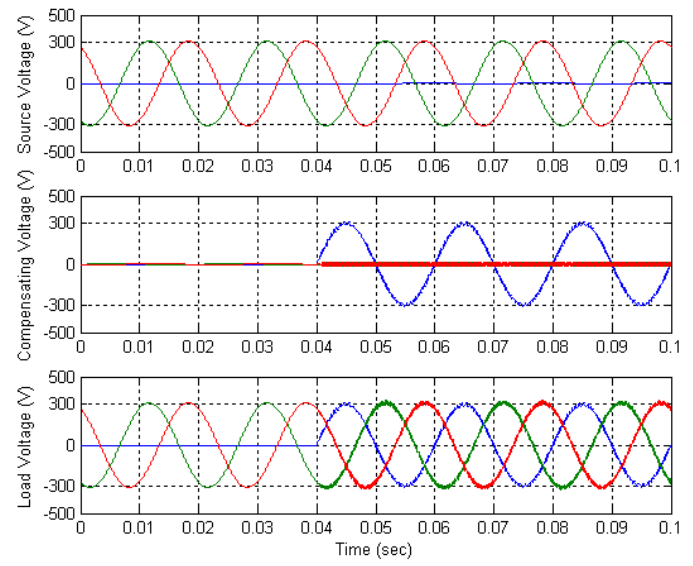

(a)
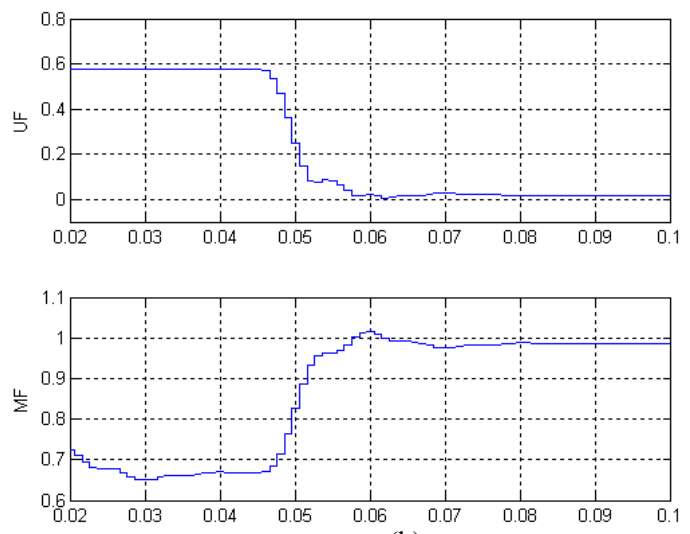

(b)

Fig. 10: (a): Load phase voltage, compensating voltage and source phase voltage in case of 1-phase loss with $|\mathrm{UF}|=0.58$ and $|\mathrm{MF}|=0.66$; (b): The corresponding UF and MF of load phase voltage

Similarly, the error between the load voltage and the required rated voltage can be quantified using a magnitude factor. The magnitude factor, $\mathrm{MF}$, is the ratio between the positive sequence voltage and a rated line-to-line voltage required by loads $\mathrm{v}_{\text {rated }}$.

$\mathrm{MF}=\frac{\mathrm{v}_{1}}{\mathrm{v}_{\text {rated }}}$

Case 1: Balance voltage sags with $|\mathrm{MF}|=0.60$

Case 2: Balance voltage swells with $|\mathrm{MF}|=1.40$

Case 3: Unbalance voltage sags with $|\mathrm{UF}|=0.20$ and $|\mathrm{MF}|=0.63$

Case 4: Unbalance voltage swells with $|\mathrm{UF}|=0.12$ and $|\mathrm{MF}|=1.31$

Case 5: 1 -phase loss with $|\mathrm{UF}|=0.58$ and $|\mathrm{MF}|=0.66$

The poor quality power supply was imposed to the load in arbitrary cases, which possible occurs in real situation. The above results show good performance of the filter in dealing with all cases of the poor power supply, which were quantified by two factorss; MF and UF. The filter could bring the load phase voltages to their normal condition after the compensating voltages were injected into the system within $2 \mathrm{msec}$. As can be seen in the UF and MF curves, they were eventually brought to the normal value at 0 and 1 respectively.

\section{CONCLUSION}

In this study, a sliding mode controller with fast reference voltage generation to correct and regulate unbalance voltage in three-phase system is presented and analyzed. The algorithm avoids the computational burden from three-symmetrical component decomposition. It was successfully implemented with the sliding mode controller. The simulation results show a very good performance of the proposed algorithm and control scheme under arbitrary fault conditions of the utility supply.

\section{ACKNOWLEDGEMENT}

This research is financially supported by 2551 yearly budget of Mahasarakham University.

\section{REFERENCES}

1. Lee, C.Y., B.K. Chen, W.J. Lee and Y.F. Hsu, 1997. Effects of various unbalanced voltages on the operation performance of an induction motor under the same voltage unbalance factor condition. Proceeding of the IEEE Conference on Industrial and Commercial Power Systems Technical, May 11-16, IEEE Xplore Press, Philadelphia, PA., USA., pp: 51-59. DOI: 10.1109/ICPS.1997.595989

2. Souto, O.C.N., J.C. de Oliveira, P.F. Ribeiro and L.M. Neto, 1998. Power quality impact on performance and associated costs of three-phase induction motors. Proceeding of the 8th International Conference on Harmonics and Quality of Power, Oct. 14-18, IEEE Xplore Press, Athens, Greece, pp: 791-797. DOI: 10.1109/ICHQP.1998.760143

3. Moran, L., P. Werlinger, J. Dixon and R. Wallace, 1995. A series active power filter which compensates current harmonics and voltage unbalance simultaneously. Proceeding of the IEEE Conference on Power Electronics Specialists, June 18-22, IEEE Xplore Press, Atlanta, GA., USA., pp: 222-227. DOI: 10.1109/PESC.1995.474816 
4. Bhavaraju, V.B. and P.N. Enjeti, 1996. An active line conditioner to balance voltages in a threephase system. IEEE Trans. Ind. Appli., 32: 287-292. DOI: $10.1109 / 28.491476$

5. Kevork Haddad and Geza Joos, 1997. Distribution system voltage regulation under fault conditions using static series regulators. Proceeding of the IEEE 32nd Conference on Industry Applications Society, Oct. 5-9, IEEE Xplore Press, New Orleans, LA., USA., pp: 1383-1389. DOI: 10.1109/IAS.1997.629037
6. Kevork Haddad and Geza Joos, 1998. A fast algorithm for voltage unbalance compensation and regulation in faulted distribution systems. Proceeding of the IEEE Conference on Applied Power Electronics and Exposition, Feb. 15-19, IEEE Xplore Press, Anaheim, CA., USA., pp: 963-969. DOI: 10.1109/APEC.1998.654015

7. Chatchanayuenyong, T. and C. Wattanasarn, 2001. A series active filter to balance and regulate voltages in a three-phase system. Eng. Trans. Mahanakorn Univ. Technol., 4: 20-25. 